\title{
The Impact of School Social Support and Bullying Victimization on Psychological Distress among California Adolescents
}

\author{
Xiaoyan Zhang ${ }^{1}$, Chaelin Karen $\mathrm{Ra}^{1}$, Donglan Zhang ${ }^{2}$, Yunting Zhang ${ }^{3}$, and Kara E. MacLeod ${ }^{4}$ \\ ${ }^{1}$ Department of Preventive Medicine, University of Southern California Keck School of Medicine \\ ${ }^{2}$ Department of Health Policy and Management, College of Public Health, University of Georgia \\ ${ }^{3}$ Shanghai Children's Medical Center, Shanghai Jiao Tong University School of Medicine, \\ Shanghai \\ ${ }^{4}$ Department of Health Policy and Management, Fielding School of Public Health, UCLA
}

\begin{abstract}
Background and Purpose: National reports showed that over $20 \%$ of high school students were victims of bullying, which could potentially lead to psychological problems. School social support may be protective against mental distress linked with victimization. This study examined the main and moderating effects of social support from adults in schools on non-specific serious psychological distress (SPD) related to victimization among California adolescents. Methods: Utilizing the 2011-2012 California Health Interview Survey (CHIS), we analyzed a representative sample of 2,799 adolescents aged 12-17 years old. Logistic regression analyses were conducted modeling the odds of SPD in relation to school social support and victimization. Results: Adolescents who were victimized were twice as likely to have SPD compared to non-victims. Higher level of social support from adults in schools was protective against SPD, but did not buffer the effect of bullying exposure. Discussion: Findings from the present study suggested that adult support from schools can help with students' psychological problems but does not appear to prevent the psychological consequences of victimization. Additional intervention is needed, above and beyond social support, to prevent victimization and its psychological consequences.
\end{abstract}

(c) 2016 Californian Journal of Health Promotion. All rights reserved.

Keywords: adolescents, victimization, mental health, school programs, social support

\section{Introduction}

Bullying is a specific form of youth violence that is defined as a repetitive, intentional form of aggression that involves a disparity of power between the victim and the perpetrator (Olweus, 1993). In 2011, over $20 \%$ of high school students in the United States reported having been bullied in school settings (Centers for Disease Control and Prevention, 2012). Among California youth, approximately $12.5 \%$ of the students experienced frequent verbal and physical victimization in the past 12 months, $22.3 \%$ of the students experienced occasional verbal and physical victimization, $20.8 \%$ of them reported verbal or relational victimization and only $44.4 \%$ of students reported having never been bullied (Tamika D. Gilreath, 2014).
Bullying can lead to poorer mental health and lower academic performance and increased violence and substance use both for the victims and the perpetrators (Bowes, Joinson, Wolke, \& Lewis, 2015; CDC, 2015; Rothon, Head, Klineberg, \& Stansfeld, 2011). The mental health of young people has been considered a major health concern, affecting $10-20 \%$ of the children and adolescents worldwide (Christian Kieling, 2011). Cross-sectional studies have linked peer victimization to psychological problems, including symptoms of anxiety and depression among adolescents (Bond L, 2001). Recent longitudinal evidence has demonstrated that victimization from bullying is associated with higher risk of sadness and suicidality among teens. (Erick Messias, 2014). Victimized adolescents are at increased risk of anxiety 
disorders in later life. (Lexine A. Stapinski, 2014).

Social support is widely recognized as a protective factor to mental health. Community interventions aimed at factors, such as, social isolation and violence have been proposed as approaches to reduce non-specific psychological distress (McVeigh, Galea, Thorpe, Maulsby, Henning, \& Sederer, 2007). The school environment may also be important for mental health and related outcomesSchools are places where both bullying and social support can take place, and they are also places where public health, mental health, and anti-bullying interventions can be implemented. For example, social interactions with teachers, administrators, and students and other school characteristics can influence perceived connectedness (Ozer, 2005), which was found protective of psychological outcomes in a national study (Resnick et al., 1997) and have been associated with fewer subsequent internalizing problems, such us depressive symptoms and anxiety in smaller longitudinal studies (Ozer, 2005; Shochet, Dadds, Ham, \& Montague, 2006).

It has been suggested that schools are able to provide instrumental support by intervening directly to decrease relational victimization (Fekkes, Pijpers, \& Verloove-Vanhorick, 2005). However, there has been some debate about what school interactions can impact mental health particularly related to bullying victimization (Ozer, 2005). In addition, few studies on the topic have separated the effects of school social support, exposure to bullying, and school and neighborhood safety on mental health. Using a large and representative sample of youth aged 12-17 in California, we conducted a study to examine: (1) whether school social support, measured by the quality of adult support in schools, and victimization are related to psychological distress and (2) if school social support attenuates the association between victimization and mental health. This research can assist in prioritizing efforts to develop school-based interventions for prevention of bullying and its possible effect on students' mental health.

\section{Methods}

\section{Study Design}

This study utilized the 2011-2012 adolescent data from the California Health Interview Survey (CHIS). CHIS is designed to provide statewide estimates for California's overall population and ethnic subgroups. CHIS is conducted using a dual-frame (80\% of the survey is conducted through landline and 20\% through cellular phone) and a multi-stage randomized sample design. For the 2011-2012 data collection process, Westat, a private firm, contracted with the UCLA Center for Health Policy Research to conduct the telephone survey. Westat staff interviewed one randomly dialed and randomly selected adult in each sampled household. Then within the sampled household, one adolescent was randomly selected if he or she was present in the household and the sampled adult was the legal guardian. Upon permission from legal guardian, the adolescent participant was interviewed directly, and the average interview time was 23 minutes. Interviews were conducted in five languages: English, Spanish, Chinese, Vietnamese, and Korean. Complete details about the questionnaire, study design, and procedures can be found in published reports (CHIS, 2014a; CHIS 2014b; CHIS 2014c; CHIS 2014d; CHIS 2014e; CHIS 2014f).

\section{Sample}

CHIS recruited 2799 adolescents aged 12-17 years who received permission from adults and represents the general non-institutionalized adolescent population living in California households. The response rate was $42.7 \%$ and $42.6 \%$ for the landline and cellular samples, respectively. All participants were included in the analyses.

\section{Measures}

Dependent Variable: Psychological Distress. A widely used, validated instrument was used to measure psychological distress. The Kessler-6 (K6) scale ranges 0-24 with a higher score indicating greater psychological distress (Kessler et al., 2003). The items included past 30-day reports of feeling "nervous," "hopeless," "restless or fidgety,” “depressed,” “everything 
was an effort” and "worthless." A score of 10 or higher on the scale indicated non-specific serious psychological distress (SPD) (Centers for Disease Control and Prevention [CDC], 2015). SPD was derived based on the scale score provided by CHIS.

Predictor Variable: Bullying. Exposure to bullying was measured in CHIS with four questions and we included the two publicly available measures. Being threatened by peers in the past 12 months was measured by the question, "In the past 12 months, how many times did someone about your age threaten to hurt you or threaten to beat you up?" This variable was a continuous variable representing the number of times and was then dichotomized by UCLA's Center for Health Policy Research for public use into the "Yes" category and the "No" category. Afraid of being beaten up at school in the past 12 months was measured by the question, "In the past 12 months, how many times on school grounds have you been afraid of being beaten up?” This variable was dichotomized by UCLA's Center for Health Policy Research for public use into the "Yes" category and the "No" category.

Predictor Variable: Adult Support from School. The School support scale (SSS) was a six-item scale and measured the quality of adult support in a school setting. The items were assessed on a 4-point Likert scale where a higher score indicated more agreement with the following statements: "There is a teacher or some other adult who really cares about me," "Who notices when I'm not there," "Who listens to me when I have something to say," "Who tells me when I do a good job," "Who always wants me to do my best," and "Who notices when I'm in a bad mood." The score ranged 624 , with higher score indicating higher level of support from adults in a school setting. The distribution of the scale was skewed, therefore, we categorized the variable into quintiles based on the unweighted distributions.

Control Variable: Adult Support from Home. Frequency of an adult around during after school hours' measures quantity of time spent with an adult outside of school, and was measured by question, "about how often is there an adult around during your after-school hours.” Possible answers to this question included: "Always", "Most of the time", "Some of the time”, "Almost never”, and "Never”.

Control Variable: Safety. Research has shown that psychological distress is associated with high levels of exposure to violence (Ozer, 2005). We controlled for personal safety by including measures of perceived environmental safety. Perceived neighborhood safety, measured with a question, "Do you feel safe in your neighborhood?" Respondents had the option of answering: "All of the time", "Most of the time", "Some of the time", and "None of the time". Perceived school safety was measured by a question, "Do you feel safe at your school?" Respondents had the option of answering: "All of the time", "Most of the time", "Some of the time", and "None of the time".

Control Variable: Physical Activity Level. Sedentary behavior and low physical activity has been associated with increased psychological distress in young children (Hamer, Stamatakis, \& Mishra, 2009). Other researchers also suggested a negative association between physical exercises and depression (Fox, 1999; Goodwin, 2003). Physical activity was measured with the question, "Not including school physical education, in the past 7 days, on how many days were you physically active for at least 60 minutes total per day?”

Socio-demographic Factors. Females tend to be more likely to have mental health symptoms compared to males, and depression varies with age (Verger, 2009). Thus the following variables were included in the regression analysis: Sex (females vs. males), Age group (12-14 vs. 1517), Race (White vs. Hispanic or Latino, Asian, African American and "other."), Family type (Married with kids vs. Single with kids), Poverty level. Poverty level (categorized as income below Federal Poverty Level (0-99\% FPL vs. $100-199 \%$ of FPL, 200-299\% of FPL, and $300 \%+$ of FPL)), and, and Language of interview English vs. "non-English). 


\section{Data Analysis}

The sample's demographic characteristics, exposure to bullying, adult social support from school and home, safety and physical activity levels were first described, stratifying by mental health status (SPD vs. non-SPD). Chi-square tests were used to test if the distribution of each categorical variable was significantly different between the group with SPD and the non-SPD group. To assess the association between exposure to bullying and quality of adult support in school settings to mental health, bivariate and multivariable logistic regressions were then conducted, estimating the odds of having SPD.

To address the secondary research objective of evaluating whether school social support modifies the association between bullying and mental health outcomes, a multivariable logistic regression including the interaction terms between school social support and bullying was also performed. There were two interaction terms in the model: (a) school social support * threatened by peers and (b) school social support * afraid of being beaten up. As some studies have reported that the school social support is only protective for girls or boys only (Davidson \& Demaray, 2007; Loukas \& Pasch, 2013), sensitivity analysis was conducted by stratifying the sample and analysis by sex.

All analyses were conducted using Stata 14.0 (StataCorp, College Station, TX). The CHIS multi-frame sampling design and complex weighting procedures were accounted for in all analyses in order to obtain the appropriate weighted estimates and standard errors.

\section{Results}

\section{Descriptive Analysis}

Table 1 includes summaries of sociodemographic characteristics, stratified by SPD vs. non-SPD status. The SPD prevalence in this population was $7.6 \%$, and the weighted SPD prevalence was $7.9 \%$. We observed that the SPD population had a significantly higher percentage of people aged 15-17 than the population without SPD (62.6\% vs. 49.8\%). Females were more likely than males to be in the SPD population (68.7\% vs. $31.3 \%)$. We did not observe a significant difference between the SPD population and the non-SPD population on ethnicity, single parent status, poverty levels, language of interview.

Table 2 presents the descriptive statistics for the predictors of interest as well as the confounding variables including adult social support from home, adolescents' perceived safety in the neighborhood or school, and their physical activity level, stratified by mental distress status. We found that a significantly higher percentage of people in the SDP population reported being threatened by peers in the past 12 months (31.8\% vs. $14.4 \%$ ) and reported being afraid of being beaten up at school in the past year $(29.9 \%$ vs. $11.9 \%)$ than that in the non-SPD population. The SPD population received lower quality of school support (39.3\% vs. $19.9 \%$ in the first quintile). The SPD group was also less likely to receive adult social support during after school hours $(5.1 \%$ vs. $1.5 \%$ almost never received support from home). We also observed a higher proportion of people in the SPD group felt unsafe some of the time than the non-SPD group $(20.1 \%$ vs. $7.5 \%$ in the neighborhood; $11.9 \%$ vs. $2.8 \%$ at school). The SDP population was also less likely to be physically active, with a lower proportion of people spent more than three days during the past week doing physical activity for at least 60 minutes $(52.8 \%$ vs. $67.2 \%)$. 
Table 1.

Sociodemographic Characteristics of Adolescents Age 12-17 Years Old, California Health Interview Survey, 2011-2012

\begin{tabular}{|c|c|c|c|c|c|c|c|}
\hline & \multicolumn{2}{|c|}{ Total } & \multicolumn{2}{|c|}{$\begin{array}{c}\text { Non-SPD } \\
\text { K6 score }<10\end{array}$} & \multicolumn{2}{|c|}{$\begin{array}{c}\text { SPD } \\
\text { K6 score }>=10\end{array}$} & \multirow[t]{2}{*}{$p$} \\
\hline & $\mathrm{N}$ & $\%$ & $\mathrm{~N}$ & $\%$ & $\mathrm{~N}$ & $\%$ & \\
\hline Age group & & & & & & & $<0.001$ \\
\hline $12-14$ & 1,378 & 49.23 & 1,298 & 50.21 & 80 & 37.38 & \\
\hline $15-17$ & 1,421 & 50.77 & 1,287 & 49.79 & 134 & 62.62 & \\
\hline Sex & & & & & & & $<0.001$ \\
\hline Male & 1369 & 48.91 & 1302 & 50.37 & 67 & 31.31 & \\
\hline Female & 1430 & 51.09 & 1283 & 49.63 & 147 & 68.69 & \\
\hline Race & & & & & & & 0.650 \\
\hline White & 1153 & 41.19 & 1066 & 41.24 & 87 & 40.65 & \\
\hline Latino & 848 & 30.3 & 779 & 30.14 & 69 & 32.24 & \\
\hline Asian & 263 & 9.4 & 246 & 9.52 & 17 & 7.94 & \\
\hline African American & 103 & 3.68 & 92 & 3.56 & 11 & 5.14 & \\
\hline Other & 432 & 15.43 & 402 & 15.55 & 30 & 14.02 & \\
\hline Family type & & & & & & & 0.238 \\
\hline Married with kids & 2195 & 78.42 & 2034 & 78.68 & 161 & 75.23 & \\
\hline Single with kids & 604 & 21.58 & 551 & 21.32 & 53 & 24.77 & \\
\hline Poverty Level & & & & & & & 0.173 \\
\hline 0-99\% FPL & 570 & 20.36 & 517 & 20.00 & 53 & 24.77 & \\
\hline 100-199\% FPL & 640 & 22.87 & 590 & 22.82 & 50 & 23.36 & \\
\hline 200-299\% FPL & 346 & 12.36 & 316 & 12.22 & 30 & 14.02 & \\
\hline $\begin{array}{l}300 \% \text { FPL and } \\
\text { above }\end{array}$ & 1243 & 44.41 & 1162 & 44.95 & 81 & 37.85 & \\
\hline Language of interview & & & & & & & 0.502 \\
\hline English & 2597 & 92.78 & 2396 & 92.69 & 201 & 93.93 & \\
\hline Spanish and other & 202 & 7.22 & 189 & 7.31 & 13 & 6.07 & \\
\hline
\end{tabular}

NOTE: N represents the unweighted frequencies; \% represents the unweighted percentage. SPD is serious non-specific psychological distress as determined from the Kessler-6. FPL is the federal poverty line.

$P$-values were obtained from the Chi-square test for categorical variables. 
Table 2.

Descriptive Statistics of Bullying, Social Support, Safety, and Psychological Distress Among Adolescents, California Health Interview Survey 2011-2012

\begin{tabular}{|c|c|c|c|c|c|c|c|}
\hline & \multicolumn{2}{|c|}{ Total } & \multicolumn{2}{|c|}{$\begin{array}{c}\text { Non-SPDK6 } \\
\text { score }<10\end{array}$} & \multicolumn{2}{|c|}{$\begin{array}{c}\text { SPD } \\
\text { K6 score }>=10\end{array}$} & \multirow[t]{2}{*}{$p$} \\
\hline & $\mathrm{N}$ & $\%$ & $\mathrm{~N}$ & $\%$ & $\mathrm{~N}$ & $\%$ & \\
\hline \multicolumn{8}{|c|}{ Exposure to bullying } \\
\hline \multicolumn{7}{|c|}{ Threatened by peers in the past 12 months } & $<0.001$ \\
\hline No & 2,324 & 84.23 & 2,180 & 85.56 & 144 & 68.25 & \\
\hline Yes & 435 & 15.77 & 368 & 14.44 & 67 & 31.75 & \\
\hline \multicolumn{7}{|c|}{ Afraid of being beaten up at school past year } & $<0.001$ \\
\hline No & 2,394 & 86.77 & 2,246 & 88.15 & 148 & 70.14 & \\
\hline Yes & 365 & 13.23 & 302 & 11.85 & 63 & 29.86 & \\
\hline \multicolumn{8}{|c|}{ Adult support from school } \\
\hline \multicolumn{7}{|c|}{ School support scale } & $<0.001$ \\
\hline 1st quintile & 597 & 21.33 & 513 & 19.85 & 84 & 39.25 & \\
\hline 2nd quintile & 754 & 26.94 & 693 & 26.81 & 61 & 28.5 & \\
\hline 3rd quintile & 616 & 22.01 & 581 & 22.48 & 35 & 16.36 & \\
\hline 4th quintile & 324 & 11.58 & 308 & 11.91 & 16 & 7.48 & \\
\hline 5th quintile & 508 & 18.15 & 490 & 18.96 & 18 & 8.41 & \\
\hline \multicolumn{8}{|c|}{ Adult support from home } \\
\hline \multicolumn{7}{|c|}{ Frequency of an adult around during after school hours } & $<0.001$ \\
\hline Always & 1,219 & 43.55 & 1,143 & 44.22 & 76 & 35.51 & \\
\hline Most of the time & 1,123 & 40.12 & 1,037 & 40.12 & 86 & 40.19 & \\
\hline Some of the time & 337 & 12.04 & 307 & 11.88 & 30 & 14.02 & \\
\hline Almost never & 71 & 2.54 & 60 & 2.32 & 11 & 5.14 & \\
\hline Never & 49 & 1.75 & 38 & 1.47 & 11 & 5.14 & \\
\hline \multicolumn{8}{|c|}{ Safety perception } \\
\hline \multicolumn{7}{|c|}{ Do you feel safe in your neighborhood } & $<0.001$ \\
\hline All of the time & 1,490 & 53.23 & 1,428 & 55.24 & 62 & 28.97 & \\
\hline Most of the time & 1,051 & 37.55 & 947 & 36.63 & 104 & 48.6 & \\
\hline Some of the time & 238 & 8.5 & 195 & 7.54 & 43 & 20.09 & \\
\hline None of the time & 20 & 0.71 & 15 & 0.58 & 5 & 2.34 & \\
\hline \multicolumn{7}{|c|}{ Do you feel safe at your school } & $<0.001$ \\
\hline All of the time & 1,990 & 72.13 & 1,890 & 74.18 & 100 & 47.39 & \\
\hline Most of the time & 656 & 23.78 & 575 & 22.57 & 81 & 38.39 & \\
\hline Some of the time & 97 & 3.52 & 72 & 2.83 & 25 & 11.85 & \\
\hline None of the time & 16 & 0.58 & 11 & 0.43 & 5 & 2.37 & \\
\hline \multicolumn{8}{|c|}{ Physically active } \\
\hline \multicolumn{7}{|c|}{ Number of days past week been physically active 60 min or more } & $<0.001$ \\
\hline$<3$ & 948 & 33.87 & 847 & 32.77 & 101 & 47.2 & \\
\hline$>=3$ & 1,851 & 66.13 & 1,738 & 67.23 & 113 & 52.8 & \\
\hline
\end{tabular}

NOTE: N represents the unweighted frequencies; \% represents the unweighted percentage.

SPD is serious non-specific psychological distress as determined from the Kessler-6.

$P$-values were obtained from the Chi-square test for categorical variables. 


\section{Logistic Regression Analyses}

Table 3 shows the results of bivariate and multivariate logistic regressions models of SPD, controlling for adult social support from home, safety level in neighborhood and school, physical activity level, age, sex, race, family type, poverty level, and language of interview. The adjusted odds ratios (OR) represented the estimated effect of exposures to bullying, school social support on adolescent's mental distress. We noticed that those adolescents who were exposed to bullying in the previous year were about $1.9(p<0.05)$ to $1.8(p<0.10)$ times more likely to have SPD compared to adolescents who did not report being bullied. Higher levels of adult social support from school, as measured by the school support scale (SSS), displayed a general protective effect against SPD $(p<0.01)$. Adolescents with high SSS scores (defined as being in third or above score quintiles) were less likely to have $\operatorname{SPD}\left(\mathrm{OR}=0.43^{\text {rd }}\right.$ vs $1^{\text {st }}$ quintile, $p$ $<0.05 ; \mathrm{OR}=0.4,4^{\text {th }}$ vs $1^{\text {st }}$ quintile, $p<0.05$; OR $=0.55^{\text {th }}$ vs $1^{\text {st }}$ quintile, $p<0.10$ ).

\section{Table 3.}

Logistic Regressions Modeling the Odds of Psychological Distress Among Adolescents, California Health Interview Survey 2011-2012

\begin{tabular}{|c|c|c|c|c|}
\hline & \multicolumn{4}{|c|}{$\begin{array}{c}\text { SPD } \\
\text { K6 score }>=10\end{array}$} \\
\hline & $\begin{array}{c}\text { Unadjusted } \\
\text { odds ratio }\end{array}$ & $\begin{array}{l}\text { 95\% Conf. } \\
\text { Interval }\end{array}$ & $\begin{array}{c}\text { Adjusted } \\
\text { odds ratio } \\
\end{array}$ & $\begin{array}{l}\text { 95\% Conf } \\
\text { Interval } \\
\end{array}$ \\
\hline \multicolumn{5}{|c|}{ Exposure to bullying } \\
\hline \multicolumn{5}{|c|}{ Threatened by peers in the past 12 months } \\
\hline No & Ref & & Ref & \\
\hline Yes & $2.302 * * *$ & $(1.445,3.668)$ & $1.876^{*}$ & $(1.092,3.223)$ \\
\hline \multicolumn{5}{|c|}{ Afraid of being beaten up at school past year } \\
\hline No & Ref & & Ref & \\
\hline Yes & $3.587 * * *$ & $(2.120,7.071)$ & $1.802 \dagger$ & $(0.938,3.462)$ \\
\hline \multicolumn{5}{|c|}{ Adult support from school } \\
\hline \multicolumn{5}{|c|}{ School support scale } \\
\hline 1st quintile & Ref & & Ref & \\
\hline 2nd quintile & 0.787 & $(0.441,1.407)$ & 1.102 & $(0.592,2.051)$ \\
\hline 3rd quintile & $0.408 * *$ & $(0.224,0.745)$ & $0.448 *$ & $(0.206,0.976)$ \\
\hline 4th quintile & $0.274 * *$ & $(0.228,0.638)$ & $0.373 *$ & $(0.148,0.938)$ \\
\hline 5th quintile & $0.312^{* *}$ & $(0.150,0.648)$ & $0.460 \dagger$ & $(0.184,1.149)$ \\
\hline
\end{tabular}

NOTE: SPD is serious non-specific psychological distress, determined using the Kessler- 6

Adjusted odds ratios were estimated from a multivariate logistic regression, controlling for age, gender, race, poverty level, family type, language of interview, adult support from home, safety perception and being physically active.

$\dagger p<0.10$; ${ }^{*} p<0.05 ; * * p<0.01 ; * * * p<0.001$

For the models that included the interaction between school social support and measures of bullying, there was no significant interaction between levels of school social support and peer threats for either males or females (Results not shown). For those who were afraid of being beaten up, there was a slight pattern of decreased odds of SPD with higher levels of school social support (males only; $p<0.10$ ); however, these relationships were highly insignificant with the addition of other covariates (Results not shown).

\section{Discussion}

Our study examined the quality of adult support in school settings as a protective factor for psychological distress and tested if it could buffer the negative effect of bullying. Among 
this current, large, representative sample of California adolescents, $16 \%$ reported an overt threat from their peers within the past year. After controlling for a number of factors, the experience of an overt threat was associated with an increased odd of almost 2-fold for nonspecific serious psychological distress. As hypothesized, higher levels of school social support were protective of psychological distress; however, did not buffer the impact of bullying.

The prevalence of victimization reported by adolescents in California was substantial but lower than the national average and that in other places. For instance, high school students in North Carolina reported 55\% of bullying, which includes $18 \%$ of cyberbullying. (Gan, 2014). Since bullying can include direct physical or verbal behaviors or indirect hostile behaviors, such as, gossip, rumor spreading, or exclusion (Kelly, 2015; Sourander, 2016), it is likely that the prevalence of the full range of bullying experiences that include verbal behaviors and cyberbully would have been much higher. Additionally, the weighted SPD prevalence in the study population was $7.9 \%$, which was similar to that reported in CHIS 2007 based on the K6 measurement (Prochaska, 2013).

We observed a protective effect of school social support on psychological distress that was consistent with the current literature, but did not found evidence of a moderating effect of social support on the negative effect of bullying. Nor did we find a gender difference in the protective effect of school social effect. This result is consistent with another study that found that measures of social support did not modify the association between bullying and mental health (Rothon, Head, Klineberg, \& Stansfeld, 2011). However, it is inconsistent with some studies conducted in middle school and high school subpopulations. In a prospective study in the US, emotional support from teachers, buffered the impact of relational victimization on the subsequent psychological problems among adolescents aged 12-19 (Yeung \& Leadbeater, 2010). In a longitudinal study of suburban middle schoolers in Texas, overt-victimization by peers predicted depressive symptoms only for girls and school connectedness buffered the impact (Loukas \& Pasch, 2013). Other studies of middle school age children suggested that school social support buffered the effect of victimization on distress only among boys (Davidson \& Demaray, 2007). Among a sample of lesbian, gay and bisexual high school students in New York City, perceived connectedness to adults in schools buffered the effects of bullying on aggressive and suicidal behaviors (Duong \& Bradshaw, 2014). These differences in study findings may reflect differences in the populations, assessment of social support, or assessment of mental health. It may also be that school social support is more relevant for buffering exposures that happen in certain school environments that involve only physical or verbal bullying. In addition, there may be cumulative effects of school social support that cannot be assessed in this cross-sectional study.

One of the strengths of the present study was the use of a measure that assessed the quality of social support from adults in a school setting, separating from peer support and school safety. Previous studies have evaluated social connectedness. There may be important differences between school connectedness and school social support. The level of connectedness to the school has generally been measured using five items (Loukas \& Pasch, 2013; McNeely, Nonnemaker, \& Blum, 2002; Ozer, 2005): "I feel safe in my school," "The teachers at this school treat students fairly", "I am happy to be at this school," "I feel like I am part of this school," and "I feel close to people at this school." It is likely that this captures social support from both peers and adults, in addition, to school safety and other school characteristics. Consistent with our hypothesis, school social support, specifically, was shown to be protective against SPD while controlling for neighborhood safety, school safety, experiences with bullying, and a number of other factors.

\section{Limitations}

CHIS data has many strengths, including a sufficient sample size and generalizability to the California non-institutionalized population. However, there were some limitations to our study. First, these data were cross-sectional. We 
cannot assess the temporal ordering of bullying, social support, and psychological outcomes. Second, this study relied on publicly available data that did not include the frequency or severity of bullying. Third, the quality of social support from family members was not directly assessed in this study. However, this study did assess other indicators and factors that would affect family functioning: household economic status, amount of time spent with adults after school, and single-parent status. Fourth, school and neighborhood safety were subjective measures and given the cross-sectional nature of the study, students who are more distressed may perceive their neighborhoods and schools more negatively.

\section{Implications}

Peer victimization can have long-term consequences (Bowes, Joinson, Wolke, \& Lewis, 2015; CDC, 2015). In a representative sample of California adolescents, $16 \%$ reported threats from their peers and this was associated with non-specific serious psychological distress (SPD) after controlling for perceived neighborhood and school safety, adult supervision at home, and a number of participant characteristics. For several decades, there has been discussion over whether social support can buffer the impact of stressful events (Caplan, 1979; Cassel, 1976; Cobb,1976). The results specific to school support have been mixed. In the present study, higher levels of school social support were protective of psychological distress but did not buffer the impact of bullying.

Poor mental health can interfere with activities of daily living and has numerous consequences for youth, including increased substance use (CDC, 2015; World Health Organization, 2015). In addition, environmental stressors, such as, neighborhood and school safety may affect academic performance (Milam, Furr-Holden, \&
Leaf, 2010). Community-based or school-based interventions may be an efficient approach to mental health, which, can impact other outcomes. Based on these findings, school social support is important for well-being but may not be able to buffer stressful events, such as, bullying.

Results from the present study suggested that the prevention of bullying should be prioritized and additional intervention is needed, above and beyond social support, to prevent bullying and its psychological consequences. For example, based on a meta-analysis, school-based antibullying programs have been able to decrease bullying by $20-23 \%$ and victimization by $17-$ 20\% (Ttofi \& Farrington, 2011). The Centers for Disease Control and Prevention have recommended improving supervision of students, implementing rules and behavior management strategies to address bullying, to implement and enforce bullying policies, and to promote cooperation among schools and parents. From an ecological perspective, some have suggested a multilevel service approach. A multilevel service delivery model could be implemented in schools where an overall intervention can be applied and then targeted interventions could be implemented for certain subpopulations with greater needs (Grapin, Sulkowski, \& Lazarus, 2015).

\section{Acknowledgements}

Dr. MacLeod was supported by Award Number T32CA009492, Cancer Control and Epidemiology Research Training, from the National Cancer Institute. The content is solely the responsibility of the authors and does not necessarily represent the official view of the National Cancer Institute or the National Institutes of Health.

\section{References}

Barker, P.R., Manderscheid, R.W., Hendershot, G.E., Jack, S.S., Schoenborn, C.A., \& Goldstrom, I. (1992) Serious mental illness and disability in the adult household population: United States, 1989. Advance data from vital and health statistics; no218. Hyattsville, Maryland: National Center for Health Statistics. Retrieved from www.cdc.gov/nchs/data/ad/ad218.pdf

Bond, L., Carlin, J. B., Thomas, L., Rubin, K., \& Patton, G. (2001). Does bullying cause emotional problems? A prospective study of young teenagers. British Medical Journal, 323(7311), 480-484. 
Zhang, X., Ra, C.K., Zhang, D., Zhang, Y., MacLeod, Z.E. / Californian Journal of Health Promotion 2016, Volume 14, Issue 2, 56 67.

Bowes, L., Joinson, C., Wolke, D., \& Lewis, G. (2015). Peer victimization during adolescence and its impact on depression in early adulthood: prospective cohort study in the United Kingdom. British Medical Journal, 350

Bronfenbrenner U. (1979). The ecology of human development. Cambridge, MA: Harvard University Press

California Health Interview Survey. (2014a). CHIS 2011-2012 Methodology Series: Report 1 - Sample Design. Los Angeles, CA: UCLA Center for Health Policy Research.

California Health Interview Survey. (2014b). CHIS 2011-2012 Methodology Series: Report 2 - Data Collection Methods. Los Angeles, CA: UCLA Center for Health Policy Research, 2014.

California Health Interview Survey. (2014c). CHIS 2011-2012 Methodology Series: Report 3 - Data Processing Procedures. Los Angeles, CA: UCLA Center for Health Policy Research, 2014.

California Health Interview Survey. (2014d). CHIS 2011-2012 Methodology Series: Report 4 - Response Rates. Los Angeles, CA: UCLA Center for Health Policy Research, 2014.

California Health Interview Survey. (2014e) CHIS 2011-2012 Methodology Series: Report 5 - Weighting and Variance Estimation. Los Angeles, CA: UCLA Center for Health Policy Research, 2014.

California Health Interview Survey. (2014f) CHIS 2011-2012 Adolescent Questionnaire -Version 15.3(2013). Los Angeles, CA: UCLA Center for Health Policy Research, 2014.

Caplan, R.D. Social support, person-environment fit and coping. In L. Ferman and J. Gordis (Eds.). Mental health and the economy. Kalamazoo, Mich.: Upjohn Foundation; 1979.

Cassel, J. (1976). The contribution of the social environment to host resistance. American Journal of Epidemiology, 14, 107 - 123.

Centers for Disease Control and Prevention. (2012). Youth Risk Behavior Surveillance Survey. Morbidity and Mortality Weekly Report, 61, 1-168

Centers for Disease Control and Prevention. (2004). Mental Illness Surveillance Among Adults in the United States by Centers for Disease Control and prevention. (http://www.cdc.gov/mmwr/preview/mmwrhtml/su6003a1.htm )

Centers for Disease Control and Prevention. (2015). http://www.cdc.gov/violenceprevention/youthviolence/bullyingresearch/. Accessed October 18, 2015

Cobb S. (1976). Presidential Address-1976. Social support as a moderator of life stress. Psychosomatic Medicine, 38(5), 300-14.

Davidson, L.M., \& Demaray, M.K. (2007). Social support as a moderator between victimization and internalizing-externalizing distress from bullying. School Psychology Review, 36(3), 383-405.

Duong, J. \& Bradshaw, C. (2014). Associations between bullying and engaging in aggressive and suicidal behaviors among sexual minority youth: the moderating role of connectedness. Journal of School Health, 84(10), 636-45.

Fekkes, M., Pijpers, F. I. M., \& Verloove-Vanhorick, S. P. (2005). Bullying: Who does what, when and where? Involvement of children, teachers, and parents in bullying behavior. Health Education Research, 20, 81-91.

Fox, K.R. (1999). The influence of physical activity on mental well-being. Public Health Nutrition, 2, 411-418. doi:10.1017/S1368980099000567.

Gan, S. S., Zhong, C., Das, S., Gan, J. S., Willis, S., \& Tully, E. (2014). The prevalence of bullying and cyberbullying in high school: a 2011 survey. International journal of adolescent medicine and health, 26(1), 27-31.

Gilreath, T. D., Astor, R. A., Estrada Jr, J. N., Benbenishty, R., \& Unger, J. B. (2014). School victimization and substance use among adolescents in California. Prevention Science, 15(6), 897906.

Goodwin, R.D. (2003). Association between physical activity and mental disorders among adults in the United States. Preventive Medicine, 36(6), 698-703.

Grapin, S.L., Sulkowski, M.L., \& Lazarus, P.J. (2016). A multilevel framework for increasing social support in schools. Contemporary School Psycholology, 20(2), 93-106. 
Zhang, X., Ra, C.K., Zhang, D., Zhang, Y., MacLeod, Z.E. / Californian Journal of Health Promotion 2016, Volume 14, Issue 2, 5667.

Hamer, M., Stamatakis, E., \& Mishra, G. (2009). Psychological distress, television viewing, and physical activity in children aged 4 to 12 years. Pediatrics, 123(5), 1263-1268. doi: 10.1542/peds.20081523

Kessler, R.C., Barker, P.R., Colpe, L.J., Epstein, J.F., Gfroerer, J.C., Hiripi, E., ... Zaslavsky, A.M. (2003). Screening for serious mental illness in the general population. Archives of General Psychiatry, 60(2), 184-189.

Kessler, R.C., Green, J.G., Gruber, M.J., Sampson, N.A., Bromet, E., Cuitan, M., ...Zaslavsky, A.M. (2010). Screening for serious mental illness in the general population with the K6 screening scale: results from the WHO World Mental Health (WMH) survey initiative. International Journal of Methods in Psychiatric Research, 19(S1), 4-22.

Kieling, C., Baker-Henningham, H., Belfer, M., Conti, G., Ertem, I., Omigbodun, O., ... \& Rahman, A. (2011). Child and adolescent mental health worldwide: evidence for action. The Lancet, 378(9801), 1515-1525.

Loukas, A., \& Pasch, K. E. (2013) Does school connectedness buffer the impact of peer victimization on early adolescents' subsequent adjustment problems? The Journal of Early Adolescence, 33(2) 245-266. doi: 10.1177/0272431611435117

McNeely, C.A., Nonnemaker, J. M., \& Blum, R.W. (2002). Promoting school connectedness: Evidence from the National Longitudinal Study of Adolescent Health. Journal of School Health, 72(4), 138-146.

McVeigh, K.H., Galea, S., Thorpe, L.E., Maulsby, C., Henning, K., \& Sederer, L.I. (2007). The epidemiology of nonspecific psychological distress in New York City, 2002 and 2003. Journal of Urban Health, 83(3), 394-405.

Messias, E., Kindrick, K., \& Castro, J. (2014). School bullying, cyberbullying, or both: correlates of teen suicidality in the 2011 CDC Youth Risk Behavior Survey. Comprehensive psychiatry, 55(5), 1063-1068.

Milam, A.J., Furr-Holden, C.D.M., \& Leaf, P.J. (2010). Perceived school and neighborhood safety, neighborhood violence, and academic achievement in urban school children. Urban Review, 42(5), 458-467.

O’Connell, P., Pepler, D., \& Craig, W. (1999). Peer involvement in bullying: insights and challenges for intervention. Journal of Adolescence, 22, 437-452.

Olweus, Dan. Bullying at school. Aggressive behavior. Springer US, 1994. 97-130.

Ozer, E.J. (2005). The impact of violence on urban adolescents: Longitudinal effects of perceived school connection and family support. Journal of Adolescent Research, 20(2), 167-192. doi: $10.1177 / 0743558404273072$

Ozer, E.J., \&Weinstein, R.S. (2004). Urban adolescents' exposure to violence: The role of support, school safety, and social constraints in a school-based sample of boys and girls. Journal of Clinical Child and Adolescent Psychology, 33(3), 463-476.

Prochaska, J. J., Sung, H. Y., Max, W., Shi, Y., \& Ong, M. (2012). Validity study of the K6 scale as a measure of moderate mental distress based on mental health treatment need and utilization. International Journal of Methods in Psychiatric Research, 21(2), 88-97.

Resnick, M.D., Bearman, P.S., Blum, R.W., Bauman, K.E., Harris, K.M., Jones, J...Udry, J.R. (1997). Protecting adolescents from harm: Findings from the National Longitudinal Study on Adolescent health. JAMA, 278(10), 823-832.

Rothon, C., Head, J., Klineberg, E., \& Stansfeld, S. (2011). Can social support protect bullied adolescents from adverse outcomes? A prospective study on the effects of bullying on the educational achievement and mental health of adolescents at secondary schools in East London. Journal of Adolescence, 34(3), 579-588.

Shochet, I.M., Dadds, M.R., Ham, D., \& Montague, R. (2006). School connectedness is an underemphasized parameter in adolescent mental health: Results of a community prediction study. Journal of Clinical Child and Adolescent Psychology, 35(2), 170-179. 
Stapinski, L. A., Bowes, L., Wolke, D., Pearson, R. M., Mahedy, L., Button, K. S., ... \& Araya, R. (2014). Peer victimization during adolescence and risk for anxiety disorders in adulthood: a prospective cohort study. Depression and Anxiety, 31(7), 574-582.

Ttofi, M.M. \& Farrington, D.P. (2011). Effectiveness of school-based programs to reduce bullying: a systematic and meta-analytic review. Journal of Experimental Criminology, 7(1): 27-56.

Verger, P., Combes, J.B., Masfety, V.K., Choquet, M., Guagliardo, V., Rouillon, F., \& Wattel, P.P. (2009). Psychological distress in first year university students: socioeconomic and academic stressors, mastery and social support in young men and women. Social Psychiatry and Psychiatric Epidemiology, 44, 643-650. doi:10.1007/s00127-008-0486-y

Yeung, R., \& Leadbeater, B. (2010). Adults make a difference: The protective effects of parent and teacher emotional support on emotional and behavioral problems of peer-victimized adolescents. Journal of Community Psychology, 38(1), 80-98.

World Health Organization (2015). Adolescent and mental health. Retrieved from: http://www.who.int/maternal_child_adolescent/topics/adolescence/mental_health/en/

\author{
Author Information \\ Correspondence should be addressed to: Kara E. MacLeod, \\ UCLA Fielding School of Public Health, 650 Charles \\ Young Dr. S., 31-269 CHS Box 951772, Los Angeles, CA, \\ 90095-1772. Email: Kara.E.M@gmail.com \\ * corresponding author
}

